\title{
Challenges in horizontal integration of eye care services into the pre-existing rural primary care structure: an operations research perspective from Nigeria
}

\author{
CHINYERE NKEMDILIM EZISI ${ }^{1, A-F}$, BONIFACE IKENNA EZE2, B, c, E, F, OBIEKWE OKOYE2, B-E, \\ CHIMDI MEMNOFU CHUKA-OKOSA ${ }^{2, \text { D-F}}$, JUDE OBINNA SHIWEOBI ${ }^{1, \mathrm{~B}-\mathrm{D}}$
}

${ }^{1}$ Department of Ophthalmology, Federal Teaching Hospital Abakiliki, Ebonyi, Nigeria

${ }^{2}$ Department of Ophthalmology, University of Nigeria Teaching Hospital (UNTH), Enugu, Nigeria

A - Study Design, B - Data Collection, C - Statistical Analysis, D - Data Interpretation, E - Manuscript Preparation, F - Literature Search, G - Funds Collection

Summary Background. The provision of population-wide, accessible, affordable, acceptable and evenly distributed qualitative eye care services remains a recurrent challenge to eye care organizations worldwide.

Objectives. To report the challenges encountered in setting up eye care service in a pre-existing primary health care facility in rural Nigeria and also audit the common causes of eye disorders in rural setting southeast of Nigeria.

Material and methods. The study was an operations research study conducted at Akpuoga-Nike between February and April 2011. Demographic and ophthalmic clinical data were collected. Health system-, community- and patient-determined challenges were catalogued and analyzed using Epi Info Statistical software for Windows, version 6. Univariate analysis was performed for data distribution testing. Analytical statistics were performed, with $p<0.05$ considered statistically significant.

Results. A total of 481 (males, 144 (29.9\%); females, 377(70.1\%)) patients aged $42.3 \pm 20.2$ SD years (range $4-80$ years) were seen. The leading eye disorders were refractive error $-28.9 \%$, and cataract $-16.4 \%$. The operations challenges encountered included difficulties with community sensitization/advocacies, inadequate infrastructure and mobile equipment, as well as lack of eye care manpower, consumables and funding deficits.

Conclusions. Health system-related issues were the main challenges encountered. Recruitment of an adequate number of rural eye care workforce, provision of needed material resources, adequate funding and engendering community participation in rural eye care delivery through grass roots advocacy and health service public education would overcome the challenges.

Key words: eye, rural health, primary care.

Ezisi CN, Eze BI, Okoye O, Chuka-Okosa CM, Shiweobi JO. Challenges in horizontal integration of eye care services into the pre-existing rural primary care structure: an operations research perspective from Nigeria. Fam Med Prim Care Rev 2017; 19(4): 366-371, doi: https://doi.org/10.5114/fmpcr.2017.70811.

\section{Background}

The provision of population-wide, accessible, affordable, acceptable and evenly distributed qualitative eye care services remains a recurrent challenge to eye care organizations worldwide. There are region-specific differences in the enormity and spectrum of these challenges, as they are more discernable in the resource-deficient settings of the low- and middle-income countries (LMICS) compared with the world's developed economies.

These challenges include changing patterns of blindness and visual impairment, inadequate human and material resources for eye care delivery, poor motivation/remuneration of the eye care workforce, as well as restricted accessibility to, and consequently, low uptake of eye care services [1]. These challenges have been variously attributed to the government's underfunding of public eye care services, economic and geographic barriers to eye care access and community-dependent political and socio-cultural factors [2]. To overcome these challenges, provision of appropriate health care infrastructure, human and material resources, recruitment and retention of an adequate number and mix of well remunerated/motivated eye care manpower and tailored interventions to engender community participation are critical. These goals are envisioned in the spirit of VISION 2020 - 'The Right to Sight', a global initiative to eliminate avoidable blindness by 2020 [3].
The Nigerian National Blindness Survey [4] found that the blindness rate, often from avoidable causes, was generally higher in rural communities than in urban populations. The pro-urban bias in eye care access inequity, the underlying cause, can be addressed by establishing fixed rural eye care centers. These centers have established accessibility, sustainability and acceptability advantages over Eye Camps, an alternative approach to rural eye care delivery, which is associated with limited patient follow-up opportunities $[5,6]$. To optimize the efficiency of resource use, cost-effectiveness and the eye care impact of these centers, the World Health Organization (WHO) recommends the utilization of the horizontal integration matrix model, as opposed to the establishment of vertical eye care projects, to incorporate primary eye care (PEC) programs into pre-existing health care (PHC) structures [5].

The Akpuoga-Nike autonomous community, located in Enugu-East LGA, and mainly populated by ethnic lbos, is a rural and predominantly agrarian community with a projected population of 3,000 . As a typical rural community, it lacks basic social amenities, such as good roads, water supply and electricity.

The Cottage Hospital (CH) is housed in a two-room bungalow and one delivery room; it has no surgical facility and has three hospital beds. It is run by one Community Health Extension Worker (CHEW). The Health Centre is run by one medical 
officer, one CHEW and one staff nurse/mid-wife. However, the medical officer and the staff nurse/midwife work in both the Cottage Hospital and the Health Center, which share one compound.

The Cottage Hospital provides obstetric care and undertakes uncomplicated deliveries, while the Health Center provides outpatient treatment for minor medical conditions. The Health personnel embark on promotive and preventive eye care activities and coordinate immunization activities.

Identifying and overcoming the operational challenges associated with the WHO-recommended integration model are critical inputs towards effective delivery and sustenance of rural eye care services. Despite this, data, especially from operations research, on this critical eye care issue remain scarce.

\section{Objectives}

1. To identify the operational challenges in incorporating eye care services into the existing rural primary care structure.

2. To asses common eye disorders in a rural Nigerian setting.

\section{Material and methods}

This cross-sectional survey was a 3-month (February 1 April 30, 2011) operations research conducted at Akpuoga-Nike, a rural community in the Enugu state of south-eastern Nigeria.

Operations research is an analytical method of problem-solving and decision-making that is useful in the management of organizations.

Operational challenges refer to problems encountered during real-life integration of eye care services into existing the primary health care structure.

\section{Ethics}

Prior to commencement of the study, ethics clearance consistent with the 1964 Helsinski Declaration, as amended in 2008 , on research involving human subjects was obtained from the Medical and Health Research Ethics Committee (Institutional Review Board) of the University of Nigeria Teaching Hospital, Ituku-Ozalla, Enugu. Study permissions were also obtained from the Enugu State Health Management Board and the Chairman of Enugu-East LGA, where the study community is located.

\section{Community selection criteria}

A 3-stage, multi-stage random sampling technique was used to select the study community. First, the Enugu East senatorial zone was randomly selected from the three senatorial zones in the state. Within the Enugu East senatorial zone, Enugu East LGA was randomly selected. Finally, the Akpuoga-Nike community was selected from a list of rural communities in Enugu East LGA. The choice of the Akpuoga-Nike community for the establishment of a rural eye clinic was further reinforced by its central location, and unhindered access by other communities, in Enugu East LGA, as well as the absence of a dedicated public or private eye care facility in the community. Additionally, the existing health care facilities in Akpuoga-Nike provided the necessary operational framework for horizontal integration of primary eye care services into the existing primary health care structure.

\section{Community sensitization and mobilization}

Community entry was initiated by administrative visits to the community leaders, town union leaders and church clergies to acquaint them with the study. Subsequently, the community's town union leader and church catechist were delegated by the community leaders to provide logistics assistance to the investigators. Through repeated announcements, the community was adequately informed of the planned establishment of the eye care facility.

\section{Community participation}

This was engendered by selecting outreach dates that did not clash with their market days or other socio-cultural events in the community. The community identified with the project by nominating two volunteers to provide on-going voluntary logistics assistance to ensure the success of the program.

\section{Training}

Three volunteers from the community, comprising the catechist and two lay people from the congregation of the local church, were trained to obtain and record patients' bio-data, organize patients for consultation, measure blood pressure and visual acuity, dispense drugs and make appointments. They also served as local interpreters of their native dialect, when needed.

\section{Pre-consultation outreach}

This one-day entry outreach introduced the planned eye care services to the community. It started with a health talk, given by one of the investigators, $\mathrm{ECN}$, on promotion of eye health, prevention of eye diseases, maintenance of good ocular health and appropriate eye health seeking behavior. They were further educated on the nature, treatment and misconceptions concerning common eye diseases in the community.

\section{Documentation of patients' data}

The entry outreach was followed by daily outpatient consultations, which comprised further health talks and clinical consultation. Each consultation was assigned a serial number and documented in the sheets of an exercise book. A questionnaire was interview-administered to obtain information on biodata, presenting complaints and findings on the examination. The diagnosis, treatment, referral plan, if applicable, and date for the next appointment was recorded in a separate register. Part of the data used for discussions, particularly on information on poor eye health literacy (patient-related factor), were obtained from direct observation and also elicited as anecdotal findings during the process of integrating eye care service into the existing primary care structure.

\section{Patients' demographics}

During the 3-month period under review, 481 outpatients were seen at the center. These comprised $144(29.9 \%)$ males aged $42.3 \pm 20.2$ SD years (range $4-80$ years) with a modal age group of $11-20$ years; and 337 (70.1\%) females aged $45.3 \pm 17.8$ SD years (range 11-90 years) with a modal age group of 31-40 years. This gave a gender ratio (male : female) of $1: 2.3$. There was no statistically significant difference between the mean ages of males and females (mean age of males vs females, 42.3 \pm 20.2 SD years vs $45.3 \pm 17.8$ SD years, $t=1.63, p=0.104$ )

The demographic characteristics of the patients are shown in Table 1.

\begin{tabular}{|l|l|l|l|}
\hline \multicolumn{4}{|l|}{ Table 1. Demographic characteristics of study subjects } \\
\hline \multirow{2}{*}{ Age (Years) } & Gender & Total (\%) $n=481$ \\
\cline { 2 - 4 } & Male & Female & \\
\hline $0-10$ & 3 & 8 & $11(2.3)$ \\
\hline $11-20$ & 35 & 24 & $59(12.3)$ \\
\hline $21-30$ & 11 & 16 & $27(5.6)$ \\
\hline $31-40$ & 5 & 80 & $85(17.7)$ \\
\hline $41-50$ & 29 & 69 & $98(20.4)$ \\
\hline $51-60$ & 24 & 58 & $82(17.0)$ \\
\hline $61-70$ & 21 & 56 & $77(16.0)$ \\
\hline $71-80$ & 11 & 18 & $29(6.0)$ \\
\hline $81-90$ & 5 & 8 & $13(2.7)$ \\
\hline Total (\%) & $\mathbf{1 4 4}$ (29.9\%) & $\mathbf{3 3 7}(\mathbf{7 0 . 1 \% )}$ & $\mathbf{4 8 1 ( 1 0 0 . 0 )}$ \\
\hline
\end{tabular}




\section{Outpatient consultation and care}

Patients were first seen by the volunteer workers who had received training on basic outpatient ophthalmic nursing care. They obtained their biodata and measured their visual acuity before sending the patients for consultation. The investigators encountered considerable antagonism from the health workers at the $\mathrm{CH}$ and $\mathrm{HC}$ for reasons of threat to their job security and undue exposure of health system deficiencies that the outreach would cause. This forced the researchers to utilize community volunteers.

Distant visual acuity was measured with the Snellen's English alphabet chart for literate patients and its tumbling E chart equivalent (Unique Opticals, Lagos, Nigeria) for illiterates. Each eye was tested separately unaided, with pinhole and with corrective spectacles where applicable. Near visual acuity was tested using Jaeger's optotype (Unique Opticals, Lagos, Nigeria) for near vision testing.

An anterior segment examination was performed using a Pen torch (Keeler Instruments, London, UK) and a head loupe (X4 magnification) (Keeler Instruments, London, UK). Fluorescein (ECWA LABORATORIES, Jos, Nigeria) staining of corneal lesions was done when necessary. Posterior segment examinations were done with a direct ophthalmoscope (Keeler Instruments, London, UK). Pupillary dilatation for examination under mydriasis was performed using tropicamide eye drops (mydria$\mathrm{cyl}^{\circledR}$ - Alcon; Belgium). Intraocular pressure was measured with the Schiotz tonometer (Reister AG, Jungingen, Germany).

After consultation, ophthalmic drugs, provided by the researchers, were dispensed at no cost to the patients, while those requiring more advanced evaluation or surgeries were referred to the University of Nigeria Teaching Hospital, Ituku-Ozalla, Enugu. Although the Health Center provided space for surgical procedures, due to lack of funds to buy the necessary equipment, it is not yet functional.

Patients requiring refraction first had objective retinoscopy followed by subjective refraction. Those needing corrective spectacles were instructed to purchase and present their own spectacle frame, and they picked up their glasses during the next clinic visit. Reading spectacles, inclusive of frame, were provided by the researchers free of charge.

\section{Data analysis}

Data on the patients' socio-demographic and clinical characteristics, as well as human and material resources, was entered into Epi Info Statistical software for Windows, version 6, (Epi Info $^{\mathrm{TM}}$, Center for Disease Control and Prevention, Atlanta, Georgia, USA) and analyzed to yield frequencies, percentages and proportions. Univariate analysis was performed for data distribution testing. The challenges encountered for delivery of eye care services were catalogued and subsequently categorized into health system-, patient- and community-related factors. Statistical tests for significance of observed inter-group differences were performed using the student $t$-test and chi-square test, as appropriate. In all comparisons, a $p<0.05$ was considered statistically significant.

\section{Results}

\section{Clinical characteristics of patients}

519 cumulative cases of ocular disorders were seen during the 3-month period of survey. Following clinical ophthalmic examinations, some patients presented with more than one clinical diagnosis. These comprised ocular anterior segment -256 (49.3\%), ocular posterior segment - $30(5.8 \%)$, and combined ocular anterior and ocular posterior segment - $233(44.9 \%)$ disorders. Eye disorders were more common in females -359
(69.2\%), compared with males - 160 (30.8\%). However, there was a male preponderance in specific eye disorders, such as pinguecula and a superficial foreign body in the ocular anterior segment and posterior staphyloma in the ocular posterior segment. The spectrum of ophthalmic disorders shows a refractive error of 150 (28.9) in the posterior anterior segment as the dominant ocular disorder, followed by cataract - 85 (16.4), in the ocular anterior segment. A superficial foreign body and posterior staphyloma, each in the ocular anterior and ocular posterior segment, accounted for the least observed eye disorders among the participants and is reported in Table 2 .

\section{Table 2. Spectrum of eye disorders among 481 outpatients}

\begin{tabular}{|l|l|l|l|}
\hline Disorder & \multicolumn{2}{|l|}{ Gender } & \\
\hline & Male & Female & $\begin{array}{l}\text { Total (\%) } \\
n=519\end{array}$ \\
\hline
\end{tabular}

\section{Anterior segment}

\begin{tabular}{|l|l|l|l|}
\hline Cataract & 24 & 61 & $85(16.4)$ \\
\hline Pterygium & 12 & 38 & $50(9.6)$ \\
\hline Allergic conjunctivitis & 7 & 26 & $33(6.4)$ \\
\hline Pinguecula & 19 & 14 & $33(6.4)$ \\
\hline Dry eye & 13 & 17 & $30(5.8)$ \\
\hline Corneal opacity & 4 & 4 & $8(1.5)$ \\
\hline Dermatochalasis & 1 & 5 & $6(1.2)$ \\
\hline Chalazion & 0 & 5 & $5(0.9)$ \\
\hline Aphakia & 1 & 3 & $4(0.7)$ \\
\hline Superficial foreign body & 2 & 0 & $2(0.4)$ \\
\hline Posterior segment & & &
\end{tabular}

\section{Posterior segment}

\begin{tabular}{|l|l|l|l|}
\hline $\begin{array}{l}\text { Age-related macular } \\
\text { degeneration }\end{array}$ & 3 & 11 & $14(2.7)$ \\
\hline Other maculopathies & 5 & 9 & $14(2.7)$ \\
\hline Posterior staphyloma & 2 & 0 & $2(0.4)$ \\
\hline Anterior and posterior segment & \multicolumn{3}{|l|}{} \\
\hline Refractive error & 37 & 113 & $150(28.9)$ \\
\hline Glaucoma & 13 & 25 & $38(7.3)$ \\
\hline Presbyopia & 17 & 28 & $45(8.7)$ \\
\hline Total (\%) & $160(30.8)$ & $\mathbf{3 5 9 ( 6 9 . 2 )}$ & $\mathbf{5 1 9 ( 1 0 0 . 0 )}$ \\
\hline
\end{tabular}

\section{Operational challenges encountered} in the provision of eye care services

These challenges were most frequently health system-related and included lack of eye care manpower and the antagonism of health workers. This is followed by community-determined factors, mainly observed as difficulty in community sensitization, mobilization and advocacy. Patient-determined factors were observed as the least operational challenges, presenting mainly as poor eye literacy (Table 3).

Table 3. Profile of challenges encountered during horizontal integration of eye care services in the Akpuoga-Nike community \begin{tabular}{|l|ll}
\hline Source of challenge & Challenge \\
\hline
\end{tabular}

\begin{tabular}{|c|c|c|}
\hline $\begin{array}{l}\text { Health system- } \\
\text {-related }\end{array}$ & $\begin{array}{l}\text { a) } \\
\text { b) } \\
\text { c) } \\
\text { d) } \\
\text { e) } \\
\text { f) }\end{array}$ & $\begin{array}{l}\text { lack of eye care manpower, } \\
\text { health workers' antagonism and } \\
\text { poor eye health literacy, } \\
\text { poor medical record management, } \\
\text { poor funding, } \\
\text { inadequate fixed infrastructure } \\
\text { and lack of materials for eye } \\
\text { care delivery, } \\
\text { lack of basic eye medications }\end{array}$ \\
\hline Patient-related & a) & poor eye health literacy \\
\hline
\end{tabular}




\begin{tabular}{|c|c|}
\hline Source of challenge & Challenge \\
\hline Community-related & $\begin{array}{l}\text { a) difficulties in community sensitiza- } \\
\text { tion, mobilization and advocacy, } \\
\text { b) poor eye health literacy among } \\
\text { community members, } \\
\text { c) socio-economic barriers, } \\
\text { d) lack of social amenities, e.g. elec- } \\
\text { tricity, good roads and portable } \\
\text { water }\end{array}$ \\
\hline
\end{tabular}

\section{Discussion}

The patients comprised more females who were frequently older, but not significantly so, than their male counterparts. There were more adult than pediatric patients. The pro-female bias in the patients' gender distribution is consistent with the findings in Nepal by Shrestha et al. [7], but differs from the male gender dominance in the series reported on by Okoye and co-workers [8] and Abou-Gareeb et al. [9]. Although attributable to the established higher prevalence of blindness and visual impairment in females [10], the observed gender profile could be partly attributed to the gender characteristics of, or intrinsic gender-determined socio-cultural barriers to eye care access among, the study center's feeder population, or both. The findings suggest the need for gender-sensitive eye care interventions, biased in favor of females, to enhance their eye care access and reduce their burden of eye disorders. Additionally, community-based measures to identify and overcome gender-specific socio-cultural barriers to eye care access are worthwhile. Similarly, the observed age profile, although partly in agreement with the reported higher uptake of eye care services at extremes of age [10], might be further accounted for by the population demographics, demographic distribution of eye diseases or age-specific socio-cultural barriers to access. To disentangle these potential confounding issues at stake, in addition to community-based measures to overcome demographic barriers to access, population-based prevalence surveys of eye diseases and current population data are needed.

Refractive error, cataract and pterygium were the leading ophthalmic disorders seen among the patients. This corroborates the observations by Isawumi et al. [11] and highlights the necessary areas to guide planners and implementers of rural eye care programs in the study community and under similar settings elsewhere in LMICs.

Health-system related challenges comprising deficient human and material resources for eye care delivery, poor medical record management, antagonism and poor eye health literacy of health workers were the most daunting operational challenges encountered.

This is consistent with WHO observations in LMICs [12] and likely reflects the general inadequacy of the eye care workforce and the reluctance of the available eye care manpower to accept rural job postings [13]. Reluctance to rural job postings has been variously attributed to inadequate socio-economic infrastructure, increased risk of disease exposure and limited health care access in rural areas [14, 15]. This has critical implications for delivery of effective and comprehensive rural eye care services and suggests the urgent need to train, recruit and retain eye care workers, of adequate number and mix, and incentivize them to accept rural postings. Most importantly, bridging the rural-urban gap in the availability of social amenities is central to this incentivizing effort.

Antagonism and poor eye health literacy of the health workers observed likely reflects the intrinsic inter-cadre rivalry in the health system and curricular deficiencies, in relation to eye health, during the training of health workers. These observa- tions corroborate the findings of Brian and co-workers [16] and Masnick [17] and further underscore their established need for in-service training, through workshops and refresher courses, on basic ophthalmic assessment and care for rural health workers; there is also a need to introduce or enrich the eye health education content of health workers' training curriculum. Additionally, the training should inculcate the spirit of inter-cadre work harmony, as envisioned in the team approach to eye care delivery, among rural health workers.

The poor management of medical records observed in the present study has been similarly reported in India by Rao et al. [18], who advocated the integration of the Geographic Information System (GIS), Monitoring Information System (MIS) and Electronic Medical Records (EMR) for efficient record keeping. However, given the insurmountable development-related barriers to these hi-tech approaches in LMICs, Mason and Pons [19] suggested a practical book keeping model in these resourceconstrained settings, as obtains in the study center.

Gross deficiencies of financial, human and material resources constituted major challenges in the present study. These challenges are consistent with the reports in Ghana [20] and India [21] and probably reflects the general trend in LMICs. The findings rationalize the urgent need for an upward review of the government's health budget in low resource settings. In a survey in Poland, Dubaj et al. have suggested that family physicians could be trained to effectively treat basic ophthalmic emergencies presenting in primary care setting as a means of solving the critical situation of deficient human resources for eye care [22]. Towards mobilizing additional funds needed to effectively overcome these challenges, the investigators recommend multi-faceted collaborations, especially with not-for-profit, non-governmental organizations [23], and advocacies to corporate organizations and philanthropic individuals. Furthermore, the concept of a Private-Public-Partnership (PPP) for health care delivery, a counterpart-funding initiative recently introduced in Nigeria's health sector to augment the government's health budget, should be extended beyond the delivery of specialized urban-based care to rural health care settings. Onakpoya et al. [24], worried by the non-availability of basic ophthalmic drugs in rural public health facilities, suggested a novel disease endemicity-guided drug distribution or disease-drug linkages, e.g. Measles-Vitamin A, Onchocerciasis-Ivermectin. This will ensure delivery of drugs to areas where the need is critical.

Poor eye health literacy was a major patient-related challenge in the present study. This has been reported elsewhere [25-27] and variously attributed to the poor general and health-specific literacy of the study center's feeder population, restricted access to mass media, poor health worker-patient communication and inappropriate format/channel/presentation of health information often beyond the consumers' processing skills. To overcome this challenge, evidence-based selection of an appropriate format and channel for eye health education is underscored. The recipients' socio-economic settings and capacity for mental processing of the contained message are critical for this selection. Where needed, a multi-sectoral collaboration, aimed at providing the basic socio-economic infrastructure, should antedate this selection.

Difficulties in community sensitization and mobilization, poor knowledge and awareness of common eye diseases and socio-economic constraints were the community-related challenges encountered. Given these scenarios, the investigators advocate the use of setting- and culturally-appropriate information dissemination tools to mobilize and educate rural community dwellers [28]. To these ends, the radio, being affordable by a majority of the rural inhabitants, comes in handy as a veritable information tool. Additionally, announcements at churches, social gatherings and village meetings should also be harnessed. As previously reported $[29,30]$, socio-economic barriers adversely impacted the uptake of eye care services and constitute 
a major logistical challenge in transporting the multi-morbid elderly to the point of delivery of eye care services. Alternatives to government-provided social amenities are usually expensive and invariably increase the translated cost of eye care services, which impede the uptake of eye care. Grass roots economic empowerment of the rural population and provision of a basic socio-economic infrastructure would help to overcome these challenges.

\section{Limitations of the study}

The conclusions drawn from this study and the extrapolation of its findings are limited by our inability to ascertain the literacy level of participants with globally acceptable research tools, its one-center design and short duration. The reliability of findings from this survey is potentially limited due to the possibility of inaccurate information from the low-literate participants. However, this was minimized by the use of local interpreters to facilitate effective communication between the participants and the researchers.

\section{Conclusions}

Although patient- and community-related challenges are contributory, health system-related factors are the main challenges to horizontal integration of eye care services into a primary health care facility in Akpuoga-Nike community. These findings rationalize the dire need to train, recruit and retain an adequate number and appropriate mix of eye care workers and incentivize them to accept rural job posting. The need for adequate health care funding, effective mobilization strategies and socio-economic empowerment of the rural population is urgent. Proactive community health partnerships and on-going in-service refresher courses for health workers are additional measures. Future multi-center, cross-cadre and cross-settings studies of a lengthy duration are warranted.

Acknowledgements. The authors wish to acknowledge the assistance of the staff of Akpuoga-Nike Health Centre, volunteer workers who assisted in the study and the entire Akpuoga-Nike community.

Source of funding: This work was funded by the authors' own resources.

Conflict of interest: The authors declare no conflict of interests.

\section{References}

1. Vision 2020. The right to sight. Global initiative for the elimination of avoidable blindness. Action plan 2006-2011 [cited 11.04.2017]. Available from URL: www.who.int/blindness/Vision2020_report.pdf. 2017.

2. Our common future. Chapter 9: The urban challenge From A/42/427. Report of the World Commission on Environment and Development [cited 11.04.2017]. Available from URL: www.un-documents.net/ocf-09.htm.

3. The new health care workforce: looking around the corner to future talent management [cited 5.08.2017]. Available from URL: http://www.deloitte.com/assets/DcomUnitedStates/Local\%20Assets/Documents/Health\%20Reform\%20lssues\%20Briefs/us_chs_NewHealthCareWorkforce_032012.pdf.

4. Abdull MM, Sivasubramanian S, Murthy GVS, et al. Causes of blindness and visual impairment in Nigeria: the Nigeria national blindness and visual impairment survey. Invest Ophthalmol Vis Sci 2009; 50(9): 4114-4120.

5. Primary Health Care. Report of International Conference on Primary Health Care: Alma-Ata Russia. WHO Health for all Series 1978: 1-3.

6. Konyama K. Essential components of primary eye care. J Comm Eye Health 1998; 11(26): 17-19.

7. Shrestha MK, Chan H, Gurung R. Gender equity in eye health of Nepal: a hospital-based study. Nepal J Ophthalmol 2012; 4(2): 277-281.

8. Okoye O, Magulike N, Chuka-Okosa C. Prevalence of human immunodeficiency virus seropositivity among eye surgical patients at a rural eye care facility in south-eastern Nigeria. Middle East Afr J Ophthalmol 2012; 19(1): 93-96.

9. Abou-Gareeb I, Lewallen S, Bassett K, et al. Gender and blindness: a meta-analysis of population-based prevalence surveys. Ophthal Epidemiol 2001; 8(1): 39-56.

10. Lewallen S, Courtright P. Blindness in Africa: present situation and future needs. Br J Ophthalmol 2001; 85(8): 897-903.

11. Isawumi MA, Hassan MB, Asekun-Olarinmoye EO, et al. Prevalence and causes of ocular morbidity seen among rural adult population of Osun State, Southwestern Nigeria. Ann Trop Med Pub Health 2013; 6(4): 465-471.

12. World Health Organization. Prevention of avoidable blindness and visual impairment: Report by the Secretariat. $62^{\text {nd }}$ World Health Assembly, A62/7, April 2009, p. 8 [cited 10.04.2017]. Available from URL: www.who.int/blindness/ACTION_PLAN_WHA62-1-English.pdf.

13. Eze BI, Maduka-Okafor FC. An assessment of the eye care workforce in Enugu state, south-eastern Nigeria. Hum Resourc Health 2009; 7: 38, doi: https://doi.org/10.1186/1478-4491-7-38.

14. Sogbesan E, Yutho U. Cambodia's National Eye Care Programme and VISION 2020: the right to sight. J Comm Eye Health 2000; 13(36): 57-59.

15. Comprehensive planning of human resource for Eye Care to meet the Goals of vision 2020: the right to sight. Report of an inter-country consultation, WHO, SEARCO, New Dehli 11-14 December 2001 [cited 30.07.2014]. Available from URL: http://laico.org/v2020resources/files/HR_OPHTHAL_WHO 1.pdf.

16. Brian G, Dalzell J, Nangala S, et al. Basic ophthalmic assessment and care for rural health workers. Aust N Z J Ophthalmol 1990; 18(1): 99-102.

17. Masnick K. Narrowing the gap between eye care needs and service provision: the service training nexus. Hum Resourc Health 2009; 7 : 35, doi: https://doi.org/10.1186/1478-4491-7-35.

18. Rao GN, Khanna RC, Athota SM, et al. Integrated model of primary and secondary eye care for underserved rural areas: the LV Prasad Eye Institute experience. Indian J Ophthalmol 2012; 60(5): 396-400.

19. Mason I, Pons J. Managing patient records in the eye unit. J Comm Eye Health 2010; 23(74): 46-47.

20. Toit RD, Faal HB, Etya'ale D, et al. Evidence for integrating eye health into primary health care in Africa: a health systems strengthening approach. BMC Health Services Research 2013; 13: 102, doi: https://doi.org/10.1186/1472-6963-13-102.

21. Ogundimu KO. Case study: improving the management of eye care programmes. J Comm Eye Health 2008; 21(68): 60-61.

22. Dubaj C, Nowak K, Pożarowska D, et al. Ophthalmic emergencies in Primary Care Practice. Fam Med Prim Care Rev 2016; 18(2): 193-199.

23. Oye JE. South-west province eye care programme, Cameroon. J Comm Eye Health 2005; 18(54): 92-99.

24. Onakpoya $\mathrm{OH}$, Adeoye $\mathrm{AO}$, Adegbehingbe $\mathrm{BO}$, et al. Assessment of human and material resources available for primary eye-care delivery in rural communities of southwestern Nigeria. West Indian Med J 2009; 58(5): 472-475.

25. Harrison TC, Mackert M, Watkins C. A qualitative analysis of health literacy issues among women with visual impairments. Res Gerontol Nurs 2010; 3(1): 49-60. 
26. Paasche-Orlow MK, Parker RM, Gazmararian JA, et al. The prevalence of limited health literacy. J Gen Intern Med 2005; 20(2): 175-184.

27. Shrestha MK, Guo CW, Maharjan N, et al. Health literacy of common ocular diseases in Nepal. BMC Ophthalmol 2014; 14: 2, doi: https://doi.org/10.1186/1471-2415-14-2.

28. Prozesky D. Advocacy for eye health. J Comm Eye Health 2007; 20(64): 57-59.

29. Kovia V, Krishnaiah S, Shamanna BR, et al. Barriers to accessing eye care services among visually impaired populations in rural Andhra Pradesh, South India. Indian J Ophthalmol 2007; 55(5): 365-371.

30. Balarabe AH, Mahmoud AO, Ayanniyi AA. The Sokoto Blind Beggars: causes of blindness and barriers to rehabilitation services. Middle East Afr J Ophthalmol 2014; 21(2): 147-152.

Tables: 3

Figures: 0

References: 30

Received: 14.06.2017

Revised: 21.08.2017

Accepted: 22.08.2017

Address for correspondence:

Obiekwe Okoye, MD

Department of Ophthalmology

University of Nigeria Teaching Hospital (UNTH)

Ituku-Ozalla, Enugu

Nigeria

Tel.: +234-803-700-7163

E-mail: eagleobi@yahoo.com 